\title{
AWEBSERVER SEBAGAI ALTERNATIF PENGGANTI XAMPP PADA PLATFORM ANDROID
}

\author{
Mega Orina Fitri \\ Prodi Sistem Informasi \\ Fakultas Sains dan Teknologi UIN Imam Bonjol Padang \\ Balai Gadang, Kota Padang, Sumatera Barat. 25171 \\ E-mail: megaof@uinib.ac.id
}

\begin{abstract}
Abstrak: Penelitian ini dilatarbelakangi oleh masalah tidak dapat menggunakan laboratorium komputer sebagai akibat dari pembelajaran online akibat pandemi COVID-19 dan juga kurangnya laptop atau komputer pribadi untuk mahasiswa. Sebagian besar mahasiswa hanya memiliki smartphone dengan platform Android untuk pembelajaran online. Tujuan dari penelitian ini adalah untuk mengukur kualitas aplikasi AWebServer yang dapat berjalan pada platform Android, sehingga dapat digunakan sebagai alternatif pengganti XAMPP. Penelitian ini merupakan penelitian kualitatif. Terdapat 30 mahasiswa program studi Sistem Informasi Fakultas Sains dan Teknologi UIN Imam Bonjol Padang yang mengikuti perkuliahan Praktikum Sistem Basis Data, sebagai subjek penelitian ini dan objek penelitian ini adalah aplikasi AWebServer. Hasil penelitian menunjukkan bahwa aplikasi AWebServer memiliki kualitas yang baik dari segi fungsionalitas, kegunaan, keandalan, efisiensi, pemeliharaan, dan portabilitas. Kesimpulannya adalah AWebServer dapat digunakan sebagai alternatif pengganti XAMPP pada platform Android.
\end{abstract}

Kata Kunci: Android, AWebServer, XAMPP

\section{PENDAHULUAN}

$\mathbf{P}$ andemi COVID-19 yang menjangkiti hampir seluruh dunia menyebabkan adanya perubahan besar pada kehidupan masyarakat, termasuk di Indonesia. Salah satunya adalah dalam proses belajar mengajar. Saat ini proses belajar belajar terutama di daerah zona merah pandemi, harus dilakukan secara daring, termasuk pada perguruan tinggi. Universitas Islam Negeri (UIN) Imam Bonjol Padang adalah salah satu universitas yang menerapkan kuliah jarak jauh secara daring bagi mahasiswa akibat masuknya kota Padang sebagai daerah zona merah pandemi ini.

Akibat dari kuliah jarak jauh ini diantaranya adalah mahasiswa tidak dapat menggunakan fasilitas kampus sebagaimana mestinya. Contohnya misalkan mahasiswa tidak dapat menggunakan laboratorium komputer sebagai tempat praktikum. Padahal masih banyak mahasiswa yang belum memiliki laptop ataupun Personal Computer (PC) sendiri karena keterbatasan ekonomi. Masih banyak mahasiswa hanya mengandalkan smartphone dengan platform Android untuk kuliah daring. Hal ini tentunya sangat menyulitkan, terutama mahasiswa program studi Sistem Informasi Fakultas Sains dan Teknologi (FST) UIN Imam Bonjol Padang yang harus sering menggunakan komputer dalam mengerjakan tugas-tugas perkuliahan seperti pemrograman dan basis data. 
Hasil survei terhadap mahasiswa angkatan 2019 dan 2020 program studi Sistem Informasi yang mengambil mata kuliah Praktikum Sistem Basis Data menunjukkan bahwa yang menggunakan laptop/PC hanya sekitar 26 orang dari total 73 mahasiswa, atau sekitar $35,6 \%$. Jumlah 26 orang itu sudah termasuk yang meminjam laptop/PC pinjaman dari teman/tetangga/kerabat dll. Sisanya hanya mengandalkan smartphone Android untuk mengikuti perkuliahan daring. Karena itu perlu dicari alternatif perangkat lunak pengganti yang dapat digunakan pada smartphone Android.

Salah satu mata kuliah yang membutuhkan perangkat lunak pengganti yang dapat berjalan pada platform Android adalah Praktikum Sistem Basis Data. Praktikum ini membutuhkan perangkat lunak yang dapat digunakan untuk mengakses DBMS (DataBase Management System) MySQL. Biasanya aplikasi paket web server open source yang digunakan adalah XAMPP (X, Apache, MySQL, PHP,Perl) yang dapat berjalan lintas platform sistem operasi seperti Windows, Linux, Solaris dan Mac OS X. Tetapi XAMPP tidak dapat berjalan pada platform Android, padahal sistem operasi ini yang digunakan pada smartphone mahasiswa.

Terdapat beberapa alternatif pengganti XAMPP yang dapat diunduh di menu Play Store smartphone Android. Salah satu aplikasi paket web server yang tersedia di Google Play Store adalah AWebServer.

1. Web Server

Istilah web server dapat ditinjau dari 2 sisi, yaitu hardware dan software. Dari sisi hardware, web server berarti suatu komputer yang berisi software web server dan komponen file website. Sedangkan dari sisi software, web server terdiri dari beberapa bagian yang mengontrol pengguna web dalam mengakses hosted files. Web server minimal berupa HTTP (HyperText Transfer Protocol) Server, yaitu suatu software yang memahami URL sebagai alamat web dan HTTP sebagai protokol browser untuk mengakses webpages.

Untuk mempublikasikan suatu website, diperlukan web server statis atau dinamis. Web server statis terdiri dari komputer (hardware) dengan HTTP server (software) yang mengirimkan file yang diminta tanpa di-update. Web server dinamis karena selain komputer dengan HTTP server, juga ditambahkan software yang biasanya berupa application server dan database. File yang diminta akan di-update oleh application server, baru dikirimkan ke browser melalui HTTP server (https://developer.mozilla.org/ en-US/docs/Learn/Common_questions/What_is_a_web_server).

\section{XAMPP}

Pada laptop atau PC umumnya sering digunakan XAMPP sebagai paket aplikasi web server. XAMPP merupakan singkatan dari X Apache MySQL PHP Perl. Simbol X (cross) menunjukkan bahwa XAMPP dapat berjalan cross (lintas) platform, yaitu pada 4 sistem operasi yang berbeda: Windows, Linux, Mac OS, dan Solaris. Sedangkan Apache merupakan modul dalam perangkat lunak XAMPP yang berfungsi sebagai web server (Binarso, 2012). Jadi dalam hal ini XAMPP berfungsi sebagai server lokal untuk mengatur berbagai jenis data website yang sedang dikembangkan.

XAMPP terbaru adalah versi 7.3.9, yang dapat diunduh secara gratis dengan label GNU General Public License. Karena itu XAMPP banyak digunakan oleh kalangan akademis seperti dosen, mahasiswa, guru, dan pelajar untuk belajar mengelola database berbasis web, serta melihat hasil desain website sebelum di-online-kan dengan menggunakan web hosting.

XAMPP dapat menggantikan peran web hosting. Caranya adalah dengan menyimpan file website ke dalam localhost. File ini kemudian dapat dipanggi melalui 
browser. XAMPP bekerja secara offline seperti web hosting pada umumnya, tetapi tidak dapat diakses oleh banyak orang (Eril, 2020).

3. AWebServer

Seiring dengan perkembangan teknologi, dimana saat ini lebih banyak digunakan perangkat mobile seperti smartphone, terutama yang berbasis Android, maka diperlukan aplikasi web server yang juga dapat berjalan pada platform Android. Dengan menggunakan aplikasi web server berbasis Android, maka smartphone tersebut dapat digunakan untuk belajar pemrograman web, membuat web dinamis, Wordpress, Joomla, dan termasuk belajar mengelola sistem basis data dengan MySQL. DBMS MySQL berguna untuk pembuatan web dinamis serta aplikasi lain yang berbasis web dan menggunakan browser.

Jika pada platform Windows, Linux, Solaris dan Mac OS dapat digunakan XAMPP, maka pada perangkat mobile dengan platform Android tersedia aplikasi AWebServer. AWebServer adalah aplikasi yang di dalamnya terdapat satu paket: Apache sebagai web server, MySQL (dulu)/MariaDb (sekarang) sebagai DBMS, dengan aplikasi berbasis web PhpMyAdmin untuk mengatur DBMS tersebut. AWebServer memungkinkan file diproses dan dikirim melalui perangkat Android ke berbagai komputer atau perangkat lain. AWebServer terintegrasi dengan FTP server untuk uploadcontent.

AWebServer dikembangkan oleh Sylkat, dengan versi terbarunya yaitu SantAndrew_16 yang baru saja dirilis pada tanggal 18 September 2020. Aplikasi ini kompatibel dengan Android 4 ke atas. Fitur-fitur yang dimiliki oleh AWebServer yaitu: Apache 2, Php 7, MySQL/MariaDb, PhpMyAdmin, Indexes Options, FTP Server, Logs Viewer, dan Text Editor. Apache 2 merupakan web server yang paling stabil bekerja pada perangkat Android.

AWebServer dapat diunduh secara gratis melalui Google Play Store di perangkat Andorid. Menunya seperti yang terlihat pada gambar berikut ini.

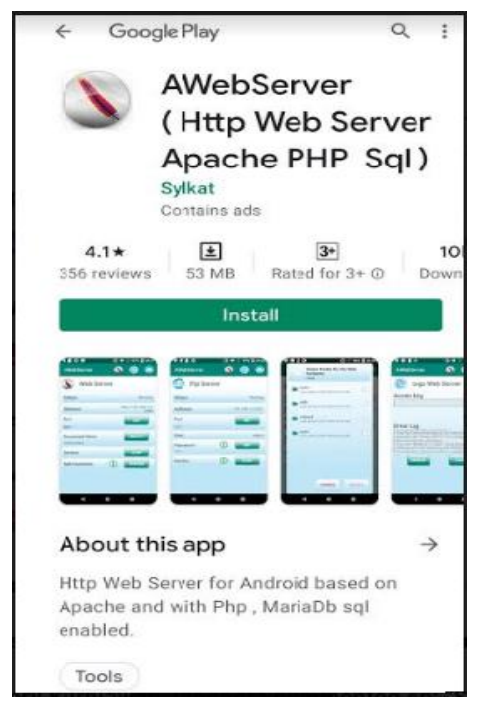

Gambar 1. Menu AWebServer di Google Play Store

\section{METODE PENELITIAN}

Jenis penelitian adalah penelitian kualitatif untuk menilai kualitas aplikasi AWebServer. Penelitian diawali dengan observasi aplikasi web server yang sesuai untuk platform Android. Dilanjutkan dengan instalasi dan penggunaan aplikasi tersebut oleh subjek penelitian di smartphone masing-masing. Kemudian diakhiri dengan penilaian 
subjek penelitian terhadap kualitas aplikasi web server tersebut. Kualitas AWebServer akan dinilai berdasarkan standar ISO 9126.

Subjek penelitian ini adalah mahasiswa program studi Sistem Informasi Fakultas Sains dan Teknologi UIN Imam Bonjol Padang yang mengambil mata kuliah Praktikum Sistem Basis Data. Subjek penelitian berjumlah 30 orang. Sedangkan objek penelitian adalah aplikasi AWebServer yang diinstal pada smartphone subjek penelitian.

Penelitian ini menggunakan teknik pengumpulan data observasi, wawancara dan angket. Sedangkan instrument penelitiannya adalah check list panduan observasi, pedoman wawancara dan angket yang berisi daftar pertanyaan. Jenis Data yang digunakan pada penelitian ini adalah:

1. Data Primer

Data primer diperoleh dari hasil observasi dari pengalaman mengajar mata kuliah Praktikum Sistem Basis Data secara daring, wawancara terhadap mahasiswa yang bersangkutan serta penyebaran dan pengisian angket.

2. Data Sekunder

Data sekunder penelitian ini diperoleh dari berbagai referensi seperti buku, artikel jurnal, modul, dan website yang berhubungan dengan masalah yang dibahas. Data sekunder digunakan sebagai kutipan tidak langsung untuk tambahan pengetahuan dan menjadi referensi dalam penelitian ini.

\section{HASIL DAN PEMBAHASAN}

Berikut adalah captures hasil instalasi dan setting yang dilakukan oleh 30 mahasiswa yang mengikuti mata kuliah Praktikum Sistem Basis Data. Setelah AWebServer diunduh dari Google Play Store, instalasi dilakukan oleh ke smartphone Android masing-masing. Tampilannya seperti pada Gambar 2.

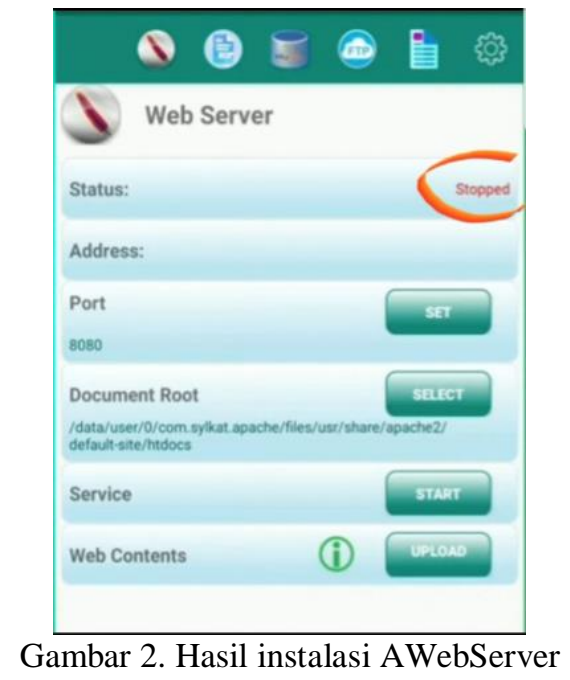

Setelah diinstal, terlihat pada Gambar 2 bahwa status Web Server (yang dilingkar merah) masih Stopped. Setelah dilakukan beberapa perubahan setting, seperti setting Port misalkan menjadi 8000 dan Document Root misalkan menjadi /sdcard/AWebserver. Tekan tombol START pada bagian menu Service untuk menjalankan di web browser, maka status Web Server akan berubah menjadi Running (yang dilingkar biru), yang artinya siap untuk digunakan. Tampilan ini dapat dilihat pada Gambar 3. 


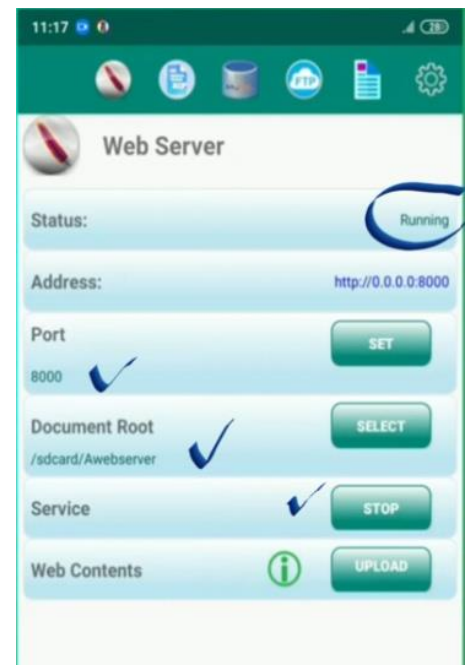

Gambar 3. Perubahan status Web Server menjadi Running

Mahasiswa kemudian mengubah Address melalui web browser, yaitu http://localhost:8000 menjadi IP Address lain, misalkan http://127.0.0.1:8000. Angka 8000 harus disesuaikan dengan Port-nya. Selanjutnya beralih ke DBMS MariaDb MySQL. Para mahasiswa menjalankan MariaDb dengan menekan tombol START pada bagian menu Service, sehingga statusnya juga menjadi Running (Gambar 4).

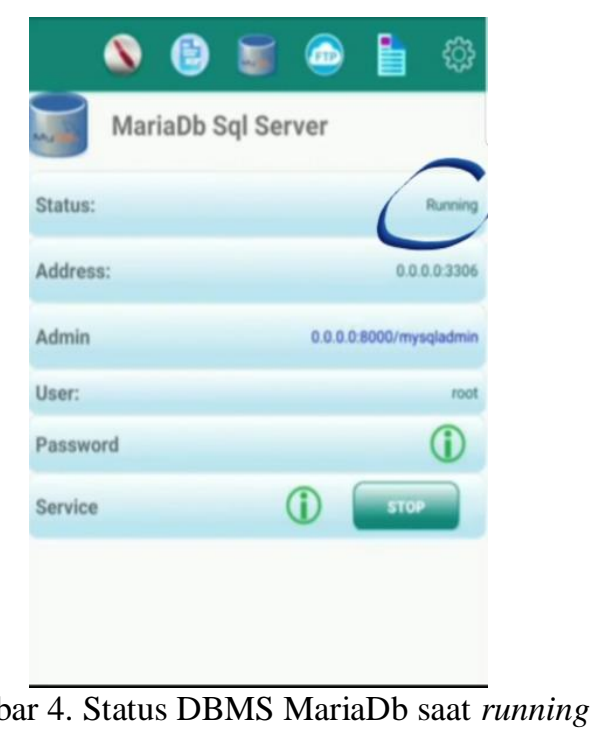

Setelah itu akses pada browser alamat http://127.0.0.1:8000/mysqladmin/. Maka akan tampil halaman awal PhpMyAdmin, dengan username: root dan password: root seperti pada Gambar 5. 


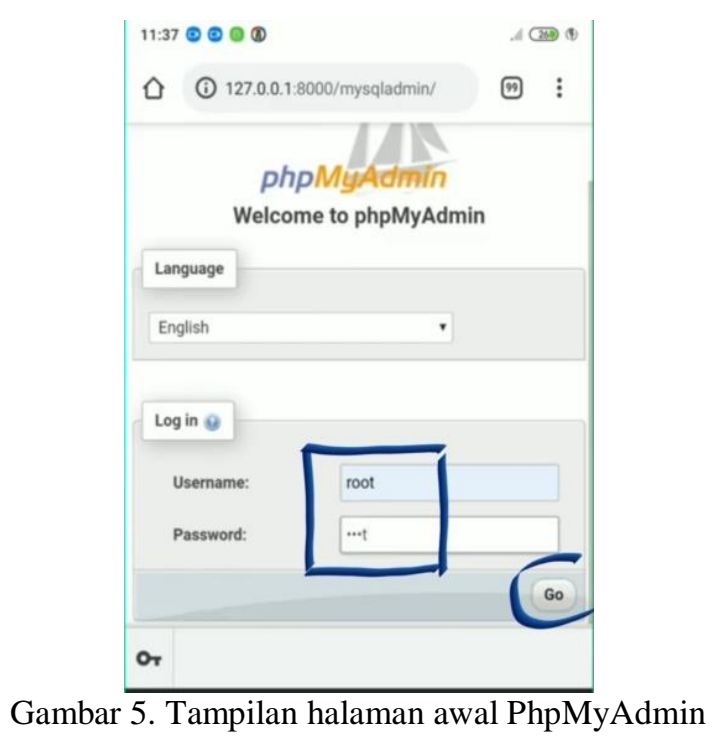

Setelah memasukkan username dan password, mahasiswa menekan tombol Go, sehingga akan muncul tampilan sperti pada Gambar 6. Artinya, aplikasi sudah siap digunakan untuk berbagai operasi SQL.

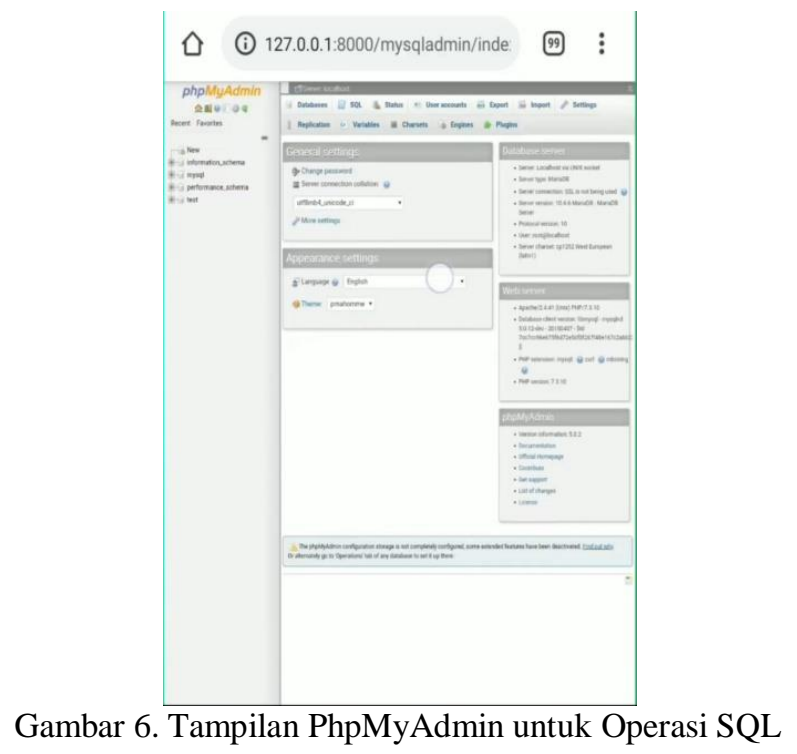

Langkah selanjutnya para mahasiswa mengelola DBMS dengan melakukan berbagai operasi SQL sesuai perintah pada Modul Praktikum Sistem Basis Data. Operasioperasi tersebut adalah Data Definition Languge (DDL), Data Manipulation Languge (DML), Data Query Languge (DQL), Fungsi Agregasi, Fungsi Teks, Fungsi Tanggal dan Waktu, Fungsi Numerik (Fitri, 2020)

Setelah itu, mahasiswa melaporkan hasilnya dengan memberikan penilaian melalui angket terhadap kualitas AWebServer sebagai pengganti XAMPP, dalam mengelola DMBS. Kualitas AWebServer diukur sesuai dengan ISO 9126. Terdapat 6 faktor kualitas software menurut ISO 9126, yaitu fungsionalitas (functionality), kehandalan (reliability), kegunaan (usability), efisiensi (efficiency), pemeliharaan (maintability), dan portabilitas (portability) (Jumyati, 2020). 
Hasil angket 30 mahasiswa terhadap kualitas aplikasi AWebServer dapat dilihat pada Tabel 1.

Tabel 1. Kualitas aplikasi AWebServer

\begin{tabular}{lccccc}
\hline Variabel & Sangat Setuju & Setuju & Kurang Setuju & Tidak Setuju & $\begin{array}{c}\text { Sangat } \\
\text { Tidak Setuju }\end{array}$ \\
\hline Fungsionalitas & 22 & 8 & 0 & 0 & 0 \\
Kehandalan & 10 & 12 & 4 & 3 & 1 \\
Kegunaan & 20 & 9 & 1 & 0 & 0 \\
Efisiensi & 10 & 12 & 5 & 3 & 0 \\
Pemeliharaan & 3 & 6 & 10 & 8 & 3 \\
Portabilitas & 10 & 10 & 5 & 3 & 2 \\
\hline
\end{tabular}

Skor diberikan dari 1 sampai 5, dengan rincian sebagai berikut:

Sangat Setuju (SS) $\quad=5$

Setuju (S) $\quad=4$

Kurang Setuju (KS) $\quad=3$

Tidak Setuju (TS) $\quad=2$

Sangat Tidak Setuju (STS) $=1$

Pengolahan data hasil angket tersebut dilakukan dengan menggunakan teori yang terdapat pada (Sugiyono, 2017).

$\mathrm{TCR}=($ Total Skor $/$ Skor Maksimum $) \times 100$

dengan:

Skor Maksimum $=\mathrm{Jml}$ Responden $\mathrm{x}$ Skor

dimana: Skor Maksimum $=30$ x $5=150$.

Jadi TCR \% untuk variabel adalah: Fungsionalitas (Functionality) 94,7\%, Kehandalan (Reliability) 78\%, Kegunaan (Usability) 92,7\%, Efisiensi (Efficiency) 79,3\%, Pemeliharaan (Maintainability) 58,7\%, dan Portabilitas (Portability )75,3\%. Menurut Sugiyono (2017), Tingkat Capaian Responden (TCR) adalah: (1) 80\% - 100\% kriterianya Sangat Baik (Sangat Kuat); (2) 60\% - 79,9\% kriterianya Baik (Kuat); (3) 40\% - 59,9\% kriterianya Cukup; (4) 20\% - 39,9\% kriterianya Kurang (Lemah); dan (5) 0\%-19,9\% termasuk kriteria yang Sangat Kurang (Sangat Lemah). Berdasarkan hasil penghitungan indeks \%, maka terdapat 2 variabel yang masuk dalam kriteria Sangat Baik pada AWebServer, yaitu Fungsionalitas dan Kegunaan. Sedangkan untuk variabel Kehandalan, Efisiensi, dan Portabilitas masuk dalam kriteria Baik. Dan dari sisi Pemeliharaan, termasuk kriteria Cukup.

Pada umumnya, hal yang menjadi kendala adalah AWebServer sering tiba-tiba berhenti sendiri, sehingga harus kembali ditekan tombol START pada bagian Service. Selain itu, cara instalasi yang agak panjang cukup menjadi kendala bagi responden. Tetapi dibandingkan dengan kendala yang dihadapi, ketersediaan AWebServer yang tidak berbayar dan tidak ada expired date adalah hal yang sangat perlu dipertimbangkan untuk 
menjadikannya sebagai alternatif pengganti XAMPP. Dengan demikian teratasi kendala ketiadaan laptop/PC mahasiswa.

\section{KESIMPULAN}

Berdasarkan pembahasan dan penilaian di atas, dapat disimpulkan bahwa AWebServer memiliki kualitas yang baik dari sisi fungsionalitas, kegunaan, kehandalan, efisiensi, pemeliharaan, dan portabilitas. Hal ini dibuktikan oleh penilaian responden bahwa AWebServer termasuk kriteria Sangat Baik dari sisi Fungsionalitas dan Kegunaan, kriteria Baik dari sisi Kehandalan, Efisiensi dan Portabilitas, serta termasuk kriteria Cukup dari sisi Pemeliharaan. Jadi dapat disimpulkan bahwa AWebServer layak dipertimbangkan sebagai alternatif pengganti XAMPP, karena dapat berjalan pada smartphone Android dengan baik. Jadi mahasiswa tetap dapat mengikuti praktikum Sistem Basis Data ataupun praktikum lainnya yang membutuhkan penggunaan paket aplikasi web server seperti XAMPP meskipun tidak memiliki laptop atau PC.

\section{DAFTAR PUSTAKA}

Binarso, Y.A., Sarwoko, E.A., \& Bahtiar, Nurdin. (2021). Pembangunan Sistem Informasi Alumni Berbasis Web pada Program Studi Teknik Informatika Universitas Diponegoro. Journal of Informatics and Technology, 1(1), 72-84.

Developer.mozilla.org, "What is a Web Server".6 Agustus 2020. https://developer.mozilla.org/enUS/docs/Learn/Common_questions/What_is_a_web_server (Diakses 09 November 2020).

Eril, "Pengertian XAMPP Lengkap dengan Fungsi dan Cara Instalasi”. 2012 https://qwords.com/blog/pengertian-xampp/ (Diakses pada 11 November 2020).

Fitri, M.O. (2020). Modul Praktikum Basis Data (SQL). Padang: Sistem Informasi FST UIN Imam Bonjol Padang.

Junyati, "Kualitas Software Model ISO 9126" https://sis.binus.ac.id/2019/04/04/kualitas-software- modeliso-9126 . 2019 (Diakses pada 14 November 2020).

Lewis, W.E. (2005). Sofware Testing and Continuous Quality Improvement. Second Edition. Florida: Auerbach Publications.

Nixon, B. (2010). Pengembangan Program Penyaringan Data Weblog untuk Analisis Pola Akses Pengunjung Webserver. [Tesis]. Depok: Universitas Indonesia.

Riza, F., Ferdiansyah, D., \& Mulyanto,F. (2018). Analisis Pengujian Kinerja Web Server yang Dibangun Atas Penyedia Layanan Virtual Private Server (VPS) Antara Digital Ocean dan VULTR. [Skripsi]. Bandung: Universitas Pasundan.

Sugiyono. (2017). Metode Penelitian Kuantitatif, Kualitatif, dan R\&D. Bandung: Alfabeta. 